\title{
Solusi Strategis Penangan Masalah Sampah Dengan Mengolah Sampah Dapur Menjadi Pupuk Organik Cair (POC): (Kasus Dua Desa Pinggir Kota di Kota Singaraja Bali)
}

\author{
I Made Pageh ${ }^{1 *}$ I Gusti Made Aryana ${ }^{1}$ \\ ${ }^{1}$ Jurusan Pendidikan Sejarah, Universitas Pendidikan Ganesha, Singaraja, Indonesia
}

\section{A R T I C L E I N F O}

Article history:

Received 31 Oktober 2018

Accepted 30 November 2018

Available online 31

Desember 2018

\section{Kata Kunci:}

Sampah; Pengolahan

Sampah; Pupuk Organik

Cair

Keywords:

Rubbish; Waste

Management; Liquid

Organic Fertilizer

\begin{abstract}
A B S T R A K
Kajian ini memiliki tujuan untuk memberikan edukasi kepada masyarakat di Desa Sari Mekar dan Desa Banyuasri di Buleleng Bali tentang pentingnya pengelolaan sampah menjadi Pupuk Organik Cair (POC). Bentuk kegiatan berupa pelatihan, pendampingan dan workshop pengelolaan sampah dapur keluarga menjadi POC. Dilaksanakan di desa Sari Mekar (2017) dan Desa Banyuasri (2018). Produk kegiatan ini adalah POC yang dapat dipergunakan sebagai penyubur tanaman dari akar maupun daun, termasuk hidroponik. POC hasil komposisasi ini dapat dikembangkan dengan menggunakan sistem peragian, dengan limbah air beras dan gula aren. Dampak langsung Kegiatan ini pada keluarga, dengan membiasakan memilah sampah organik dengan anorganik, tidak membuang sampah sembarangan, dan tumbuh kesadaran ekonomis bahwa sampah dapat berubah dari masalah menjadi berkah. Sampah organik dapur adalah sampah terbanyak menggunakan
\end{abstract} palastik, strofum, dan kemasan makanan fastfood. Dengan melakukan pemilahan sampah dari rumah tangga dapat berdampak langsung pada lingkungan paling hulu dalam siklus sampah di dua desa ini. Sedangkan sampah anorganik dapat dilola menjadi barang berguna lainnya, atau dijual langsung pada bank sampah yang sudah tersedia di Buleleng. Dengan demikian pengabdian ini menjadi sangat strategis dalam menangani masalah sampah perkotaan dan pedesaan.

\begin{abstract}
A B S T R A C T
This study aims to educate the public in Sari Mekar Village and Banyuasri Village in Buleleng Bali about the importance of waste management into Liquid Organic Fertilizer (POC). Forms of activities in the form of training, mentoring and workshops on family kitchen waste management become POC. Conducted in the villages of Sari Mekar (2017) and Desa Banyuasri (2018). The product of this activity is POC which can be used as a fertilizer for plants from roots and leaves, including hydroponics. The results of this compost POC can be developed using a fermentation system, with waste water from rice and palm sugar. The direct impact of this activity on the family, by getting used to sorting organic waste inorganic, not littering, and growing economic awareness that garbage can change from a problem to a blessing. Kitchen organic waste is the most waste using palastik, strofum, and fast food packaging. By sorting waste from households it can have a direct impact on the upstream environment in the garbage cycle in these two villages. Whereas inorganic waste can be melola into other useful items, or sold directly to garbage banks that are already available in Buleleng. Thus this service has become very strategic in dealing with urban and rural waste problems.
\end{abstract}

Copyright (C) Universitas Pendidikan Ganesha. All rights reserved. 


\section{Pendahuluan}

Pertumbuhan penduduk perkotaan memberikan tekanan terhadap lingkungan. Berbagai aktivitas masyarakat telah mendorong terjadinya percepatan pencemaran lingkungan, baik pencemaran terhadap air, tanah, maupun emisi gas buang mesin. Meningkatnya pencemaran tersebut telah menimbulkan dampak yang serius terhadap kualitas lingkungan ditunjukkan dari menurunnya daya dukung lingkungan, rusaknya habitat dan ekosistem dan terjadinya pemanasan global. Permasalahan lingkungan menjadi sorotan adalah sampah. Permasalahan sampah dihadapi oleh hampir seluruh negara sedang berkembang di dunia. Setiap hari rata-rata setiap harinya menghasilkan puluhan ton sampah. Sampah-sampah itu dibuang begitu saja di tempat pembuangan sampah akhir tanpa diolah, sehingga masalah sampingannya semakin besar seperti bau amis, habitat lalat, kebakaran, dan memunculkan berbagai penyakit di lingkungan lokasi pengabdian ini. Sampah berasal dari rumah tangga, pertanian, perkantoran, perusahaan, rumah sakit, pasar, dan sebagainya. Secara garis besar, kasus sampah di dua desa ini, yaitu: Sampah Organik, adalah sampah-sampah yang basah bercampur plastik dan kemasan makanan. Yang berasal dari sampah dapur seperti: sisa-sisa makanan, buah-buahan, sayursayuran dan lain-lain yang dapat mengalami pembusukan secara alami.Sampah anorganik, adalah sampah-sampah yang kering.Sampah ini berasal dari logam, besi, kaleng, plastik, karet, botol, dan lain-lain yang tidak dapat mengalami pembusukan secara alami. Sampah berbahaya, adalah sampah-sampah berbahaya seperti baterai, botol racun nyamuk, jarum suntik bekas, rondsokan TV, strofum dan lain-lain.

Sampah di Desa Sari Mekar dan Banyuasri perlu penanganan yang baik sehingga bisa mencegah dampak negatif yang ditimbulkannya. Salah satu caranya adalah dengan menggunakan pendekatan reuse, reduce, recycle (3R). Memanfaatkan sampah yang tidak bisa didaur ulang dan digunakan kembali menjadi barang yang memiliki nilai ekonomi, perlu ada kegiatan mengolah sampah dapur keluarga menjadi pupuk padat dan pupuk organik cair (POC).

Sampah di dua desa ini sangat menentukan citra kota, karena dekat dengan kebeadaan kota Singaraja, perkembangan penduduk yang sangat pesat dan membawa sampah semakin menumpuk dan menjepit kota dari timur dan dari barat. Pola pemukian masyarakat di dua desa ini memusat dan berada di perbatasan kota.

Pola pemukiman penduduk desa ini jika dilihat dari ideologi Tri Hita Karana terbagi menjadi tiga kawasan yakni kawasan parahyangan, pawongan dan palemahan. Falsafah Tri Hita Karana yang menekankan pada teori keseimbangan menyatakan 3 tiga penyebab kesejahteraan (Pageh, 2012). Parahyangan bisa dilihat dari adanya tempat suci berupa pura yaitu pura Tri Kahyangan, Pura Keluarga, dan Pura Swagina seperti Pura Bedugul yang berkaitan dengan pertanian. Pawongan bisa dilihat dari adanya masyarakat desa yang mendiami wilayah desa ini. Masyarakat yang tinggal ini memanfaatkan areal paleman desa di daerah ini untuk berbagai kepentingannya. Secara umum konsep Tri Hita Karana itu telah menjadi dasar dalam setiap tindak masyarakat di dua desa ini. Hanya saja di dua desa ini pola penempatan parhyangan terpusat dengan lokasi palemahan, dan Banyuasri memiliki Pura Desa di sebrang sungai, tidak lazim di Bali, demiian juga penempatan setra ada di hulun desa, maklum karena sejarah desa ini adalah palemahan dimiliki oleh Banjar Tegal.

Secara khusus salah satu prinsip keseimbangan yang harus diwujudkan dalam falsafah Tri Hita Karana adalah keseimbangan hubungan dan tanggung jawab antara manusia dan alam sekitarnya (Prinsip Palemahan). Aspek Palemahan mengandung makna keterkaitan hubungan antara manusia terhadap lingkungan alam. Lingkungan alam harus dijaga agar dapat memberikan manfaat bagi umat manusia. Hubungan yang harmonis antara sesama manusia dengan alam dikembangkan dari perumpamaan bagaikan janin dalam rahim. Dalam hal ini, manusia adalah janin, dan lingkungan adalah rahim. Jika manusia merusak lingkungan, maka dia sendirilah yang terlebih dahulu akan musnah. Pandangan ini selanjutnya dijabarkan dalam bentuk tindakan dan pandangan sebagai berikut: (1) Meyakini bahwa manusia adalah bagian dari alam dalam sistem kesemestaan; (2) Meyakini bahwa kebahagiaan hidup ditentukan oleh kemampuan untuk mengadaptasikan diri dan memanfaatkan hukum-hukum alam; (3) Meyakini bahwa kelestarian alam merupakan prasyarat mendapatkan kedamaian dan kebahagiaan hidup; (4) Meyakini bahwa waktu merupakan faktor pembatas segala aktivitas dan tata nilai yang 
besifat tentatif kondisional; (5) Meyakini keberadaan makhluk dan alam gaib serta upaya penyerasian diri dengan kekuatan gaib tersebut (Suja, 2003).

Berkenan dengan hal itu karena pesatnya perkembangan jumlah penduduk serta pembangunan pemukiman telah mempengaruhi tata ruang (palemahan) di dua desa in yaitu Sari Mekar dan Banyuasri, terutama berkaitan dengan ruang untuk membuang sampah. Pemandangan yang demikian menurut Kepada Desanya disebabkan oleh: pertama, belum adanya kesadaran dari masyarakat desa tentang pentingnya membuang sampah pada tempatnya; kedua, terbatasnya ruang pembuangan sampah karena ruang padat huni; ketiga, belum ada kesadaran tentang pengelolaan sampah agar memiliki nilai guna dan nilai ekonomis dari sampah dapur.Oleh karena itu kepala Desa Sari Mekar dan Banyuasri sangat berharap adanya bantuan dari pihak luar untuk memberikan edukasi tentang pengelolaan sampah di dua desa ini.

Demikianlah situasi dua desa ini sehingga kami tertarik mengadakan pengabdian masyarakat tahun 2017 di Desa Makar sari dan Tahun 2018 di Desa Banyuasri, guna mewujudkan visi dan misi undiksha berbasis Tri Hita Karana. Seluruh insan Undiksha dituntut untuk mewujudkan visi dan missi itu, di samping tujuan pemerintah Bali menjadi Bali sebagai kawasan yang Green and Clean.

Oleh sebab itu maka perlu ada langkah nyata dalam mewujudkan visi dan missi itu langkah awal yang bisa dilakukan adalah melalui pemberian pemahanan tentang arti penting kebersihan dan pemanfaatan sampah dengan memakai gerakan 3R (Reuse, Reduce, Recycle) menggunakan, mengurangi dan mendaurulang sampah dapur sebagai sampah palinghulu. Reuse bisa dengan menggunakan barang yang masih bisa digunakan, reduce melalui pengurangan sampah, dan recycle dengan mendaur ulang kembali sampah-sampah yang ada dilingkungan untuk dijadikan barang lainnya yang lebih bernilai ekonomi, yaitu sampah menjadi pupuk padat dan pupuk cair (POC), menggunakan composer sederhana, yang telah digunakan di masyarakat oleh kelompok penggiat Lingkungan di Lovina dan sekitarnya.

\section{Metode}

Pelaksanaan kegiatan Pengabdian Kepada Masyarakat ini dilaksanakan melalui tiga tahapan utama yaitu 1) Ceramah dan diskusi awal untuk menanamkan pemahaman dan menyatukan pikiran, perkataan, dan perbuatan (konsep trikaya parisuda); 2 ) Workshop yaitu kegiatan pelatihan membuat composer sederhana dan penggunaannya, dan 3) Pendampingan untuk mengevaluasi proses pelaksanaan kegiatan tersebut

\section{Hasil dan pembahasan}

Merujuk UU RI nomor 18 tahun 2008 pasal 1 (1) tentang pengelolaan sampah. Selanjutnya PP Nomor 81 Tahun 2012 tentang pengelolaan sampah rumah tangga dan sampah sejenis sampah rumah tangga pada pasal 1 (1) menjelaskan sampah rumah tangga adalah limbah yang berasal dari kegiatan sehari-hari dalam rumah tangga, yang tidak termasuk tinja dan sampah spesifik. Lebih lanjut menurut UU RI nomor 18 tahun 2008 pasal 1 (5) tentang pengelolaan sampah, yang dimaksud dengan pengelolaan sampah adalah kegiatan yang sistematis, menyeluruh, dan berkesinambungan yang meliputi pengurangan dan penanganan sampah. Secara spesifik Perda Kabupaten Buleleng Nomor 1 tahun 2013 membahas tentang Pengelolaan sampah menjelaskannya, pada Pasal 1 (12) Pengurangan sampah adalah rangkaian upaya mengurangi timbunan sampah, pendaur ulangan sampah, dan/atau pemanfaatan kembali sampah. Pasal 1 (13) penanganan sampah adalah rangakian upaya dalam pengelolaan sampah yang meliputi pemilahan, pengumpulan, pengangkutan, pengolahan, dan pemrosesan akhir sampah. Pasal 1 (14) Pemilahan adalah upaya penanganan sampah dalam bentuk pengelompokan dan pemisahan sampah sesuai jenis, jumlah dan/atau sifat sampah.

Menurut Suyoto (2008) tindakan yang dapat dilakukan berkaitan dengan program (1) reduce dengan menghindari pemakaian dan pembelian produk yang menghasilkan sampah, menggunakan kembali wadah/ kemasan untuk fungsi yang sama atau fungsi lain, menggunakan baterai yang dapat di charge kembali, menjual atau memberikan sampah yang terpilah kepada pihak yang memerlukan, mengubah pola makan ke pola pola makan sehat, dan membeli barang 
dalam kemasan besar (versus kemasan sachet), (2) reuse adalah kegiatan menggunakan kembali material yang masih layak pakai. Menurut Suyoto (2008) tindakan yang dapat dilakukan berkaitan dengan program reduce memilih produk kemasan yang dapat didaur ulang, menggunakan produk yang dapat diisi ulang (refill), mengurangi penggunaan bahan sekali pakai, plastik kresek digunakan untuk tempat sampah,dan kaleng/ baskom besar digunakan untuk pot bunga atau tempat sampah, dan (3) recycle adalah kegiatan mengolah kembali atau mendaurulang sampah. Menurut Suyoto (2008) tindakan yang dapat dilakukan berkaitan dengan program recycle sebagai berikut. (1) mengubah sampah plastik menjadi souvenir (2) lakukan pengolahan sampah organik menjadi kompos, (3) mengubah sampah kertas menjadi lukisan atau mainan miniatur.

Salah satu solusi yang dilatihkan dalam kegiatan ini adalah menyelesaikan masalah sampah dari hulunya yaitu dapur keluarga. Solusinya adalah pengelolaan sampah organik menjadi POC (Pupuk Organik Cair) yang melalui tahapan berikut ini:

1) Pilah sampah dapur antara sampah organik dengan anorganik.

2) Siapkan tabung komposer

3) Masukan serabut kelapa, atau kangkung pada bagian bawah tabung (menghasilkan kandungan $\mathrm{K}$ )

4) Masukan batang pisang yang sudah dihaluskan (unsur P)

5) Masukkan potongan nenas (unsur N)

6) Masukan sampah-sampah organik, daun, sayur, buah dalam tabung komposer.

7) Air yang keluar dari composer selanjutnya menjadi bioaktivator (campurkan dengan air beras, gula aren, dan air composer pertama-tama itu), selanjutnya menjadi activator.

8) Tunggu 7-10 hari cairan akan keluar dari tabung komposter

9) Setiap memasukan sampah semprotkan untuk membasahi sampah dengan bioaktivator.

10) Kumpulkan cairan tersebut, kemudian lakukan permentasi dengan perbandingan 1 liter cairan di atas: 10 liter air beras; 15 liter air; 0,5 kg gula pasir; $1 \mathrm{~kg}$ gula merah

11) Fermentasi 10-14 hari

12) Pupuk organik cair sudah siap diaplikasikan keberbagai tanaman dengan perbandingan 1 liter POC: 5 liter air. (cf. Brosur POC, I Wayan Ariawan aktivis lingkungan dari SidatapaBuleleng).

Melalui pengelolaan sampah dapur inilah nantinya permasalahan sampah keluarga akan terselesaikan, karena menyentuh hulu sampah yaitu sampah dapur keluarga.

\subsection{Pengelolaan Sampah Organik menjadi POC Sebuah Solusi}

Berdasarkan pada persoalan yang ada di lokasi pelaksanaan kegiatan pengabdian kepada masyarakat yaitu di desa Sari Mekar dan Banyuasri. Maka ada beberapa permasalahan urgen yang harus segera diberikan pemecahannya. Pertama adalah berkaitan dengan pemahaman dan kesadaran masyarakat tentang sampah. Masalah kedua ruang tempat sampah dan tentang nilai guna setelah sampah dikelola. Oleh karena itu pemecahan masalah dipecahkan di hulu yaitu di keluarga, dengan memberikan pemahaman tentang sampah, serta membuang sampah di tempat sembarangan merupakan pelanggaran terhadap falsafah trihita karana, karena dapat mengganggu buta kala-buta kali yang tinggal di got, sungai, selokan, dan tempat makhluk lain di bawah manusia. Pemahaman Pamali (pamalik) memang lumrah di Bali, hanya saja pandangan Sungai, Selokan, dan ruang terbuka lainnya sebagai teba perlu didekontruksi aga rtumbuh kesadaran takut membuang sampah sembarangan. Karena berdampak pada pemalik dan kehidupan manusia. Baru setelah hal itu dipahami dengan memakai pendekatan ideogi Tri Hita Karana, Tri Kaya Parisuda dan 3 R (reuse, reduce, recycle), kemudian diperkenalkan dengan alat bantu teknologi berupa composer sederhana yang dapat dibuat dengan mudah dan dapat membantu pengelolaan sampah organic, sedangkan amorganiknya dibuatkan koperasi sampah, dengan pola pengambilan berkala, dan dijadikan tabungan masyarakat yang dapat diambil kemudian misalnya disepakati hari raya tertentu Galungan atau Nyepi. Alur kerangka pemecahan sampah dapur dalampelatihan ini dapat dilihat pada Gambar 1. 


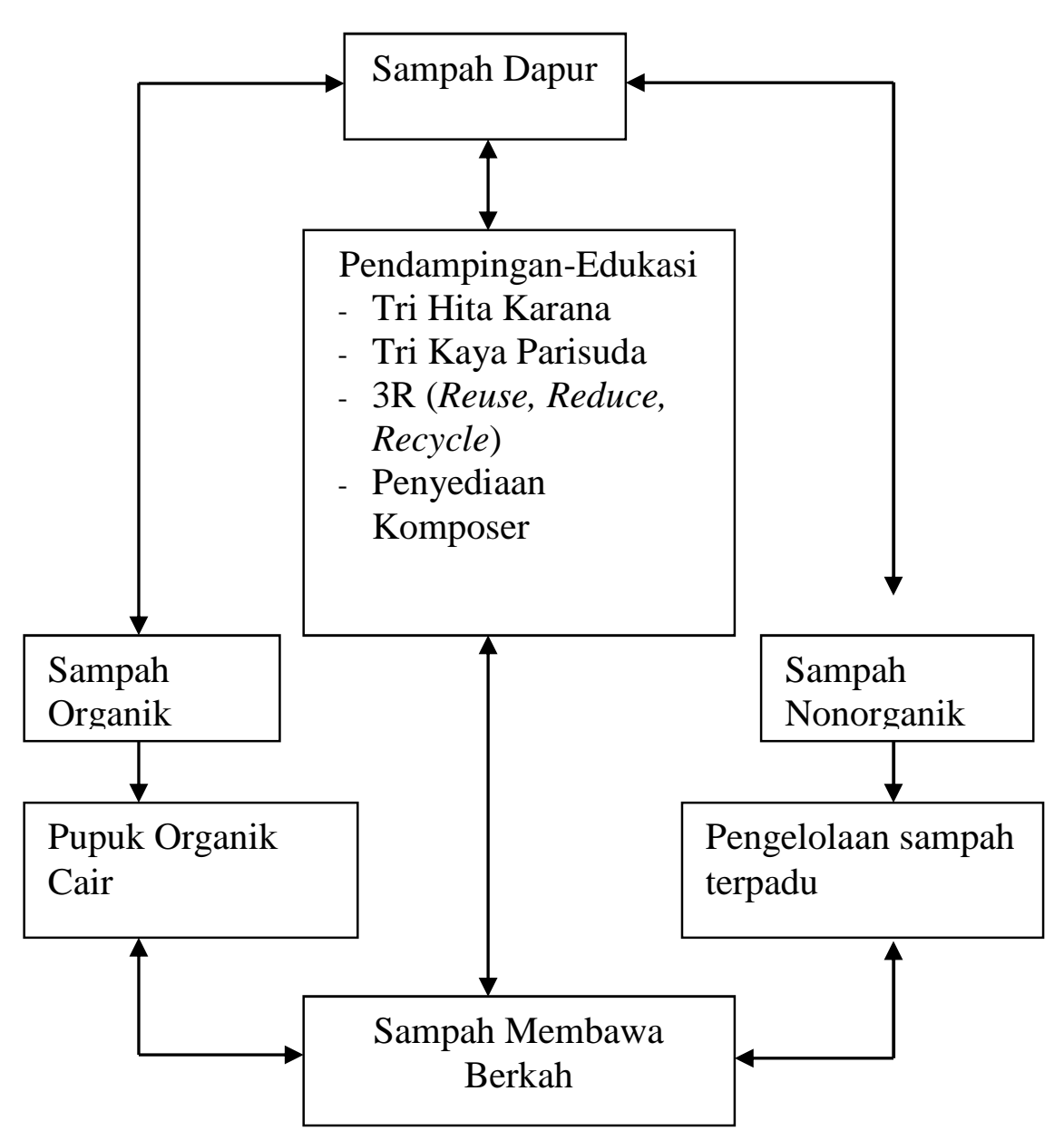

Gambar 1. Kerangka Pemecahan Masalah Sampah

Gambar 1 menjelaskan bahwa sampah khususnya sampah dapur jika dipahami dengan konsep tri hita karana, konsep tri kaya parisudha, 3R (reuse, reduse, recycle) maka secara umum pemanfaatan sampah dan mengolahnya dengan teknologi sederhana dan tepat guna, keuntungan ekonomis datang dari POC dan tabungan sampah anorganik, tetapi sasaran utamanya penyelamatan lingkungan dalam jangka panjang memulai dari factor ekonomis. Oleh karena itu tahapan dimulai dengan pendampingan pembuatan komposer, pembuatan POC mengandung NPK, kemudian mempermentasi air beras yang terbuang percuma setiap hari, menjadi tertampung dan terpermentasi. Kemudian setelah mereka memiliki pemahaman tentang sampah dan pengelolaanya maka langkah selanjutnya adalah dengan memberikan pendampingan pengelolaan sampah organik menjadi POC (Pupuk Organik Cair).

Melalui kegiatan awal ini diharapkan selanjutnya masyarakat semakin sadar akan pentingnya pengelolaan sampah sehingga bisa mengurangi sampah yang ada di sekitarnya. Untuk mudahnya lihatlah prosedur pengelolaan sampah dapur keluarga menjadi POC.

Terlaksanaanya kegiatan pengelolaan sampah dapur organik ini yang dimulai dari hulu atau sumber primer sampah, dapat menjadi solusi jitu untuk menumbuhkan kesadaran lingkungan, menyelesaikan permasalahan sampah langsung dari sumber masalahnya. Oleh karena begitu strategisnya penyelesaian masalah sampah dapur dengan komposer, perlu mendapat dukungan dari berbagai pihak sehingga kegiatan seperti ini bisa terus berlanjut dan menjadi salah satu program prioritas demi mewujudkan masyarakat sadar sampah dan saar lingkungan dari bawah, sehingga Bali memjadi bersih dan bebas dari sampah (green and clean). 


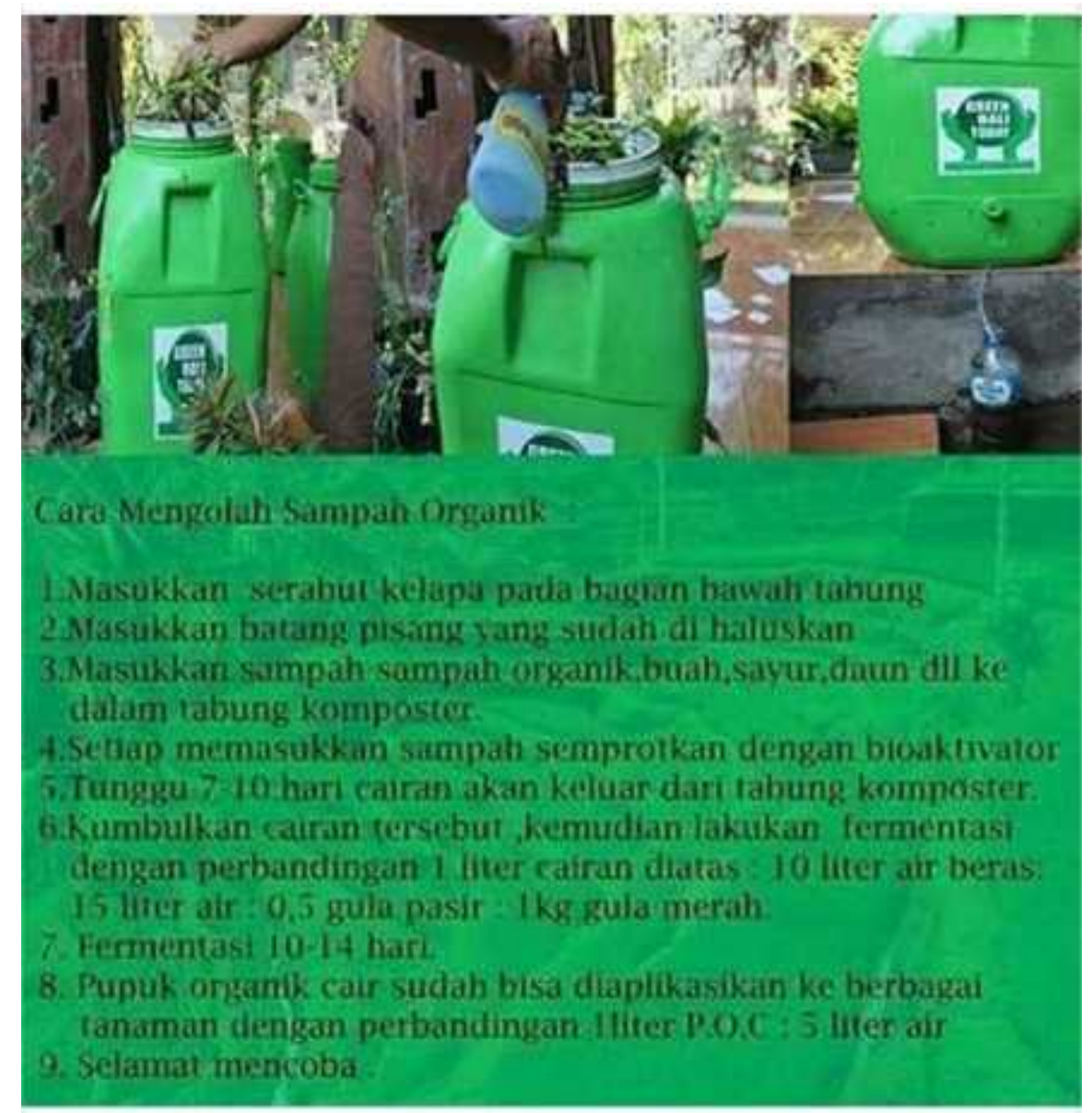

Gambar 2. Cara Pengelolaan Sampah Organik menjadi POC (Pupuk Organik Cair)

\section{Simpulan dan saran}

Pengelolaan sampah yang selama ini dilakukan sering hanya dimulai dari pinggiran tidak menyentuh sumber masalah sampah itu yaitu dapur. Program Pengabdian Kepada Masyarakat melalui Pengelolaan Sampah Organik dapur menjadi Pupuk Organik Cair (POC) ini menjadi solusi strategis untuk menyelesaikan masalah sampah langsung dari hulunya. Oleh karena itu perlu terus dikembangkan dan dijadikan sebagai salah satu program unggulan dalam penanganan sampah berbasis keluarga. Melalui kesadaran lingkungan di keluarga maka penyelesaian masalah sampah mmenjadi lebih menukik penyelesaiannya dari sumber primer dan hulunya.

\section{Daftar Rujukan}

Pageh, I Made. 2012. Revitalisasi Ideologi Kearifan Lokal Bali Aga Berbasis Kearifan Lokal Tri Hita Karana di Era Globalisasi. Laporan Penelitian. Universitas Pendidikan Ganesha Singaraja.

PP Nomor 81 Tahun 2012 tentang Pengelolaan Sampah Rumah Tangga Dan Sampah Sejenis Sampah Rumah Tangga.

Perda Kab. Buleleng Nomor 1 tahun 2013 tentang Pengelolaan Sampah.

Suja, I Wayan. 2003. Keseimbangan antar unsur Tri Hita Karana, Laporan Penelitian. KIP Negeri Singaraja.

Suyoto, Bagong. 2008. Penomena Gerakan Mengelola Sampah. Jakarta: PT Prima Infosarana Media.

UU RI nomor 18 tahun 2008 tentang Pengelolaan Sampah. 